\title{
NUTRITIONAL STATUS AND GROWTH PARAMETERS OF SCHOOL-AGE ROMA CHILDREN IN THE REPUBLIC OF MACEDONIA
}

\author{
Igor Spiroski ${ }^{1,2}$, Zlatanka Dimitrovska ${ }^{1}$, Dragan Gjorgjev ${ }^{1,2}$, Vladimir Mikik ${ }^{1}$, Vesna Efremova-Stefanoska ${ }^{1}$, \\ Daniela Naunova-Spiroska ${ }^{3}$, Vladimir Kendrovski ${ }^{1,2}$ \\ ${ }^{1}$ Institute of Public Health of the Republic of Macedonia, Skopje, Republic of Macedonia \\ ${ }^{2}$ Faculty of Medicine, Ss. Cyril and Methodius University, Skopje, Republic of Macedonia \\ ${ }^{3}$ Avicena Diagnostica, Skopje, Republic of Macedonia
}

\section{SUMMARY}

Main objective of the study was to assess the nutritional status of school age Roma children in Macedonia in order to detect precursors of possible health risks at an early age. The study was designed as a comparative case control study. Study group consisted of 229 Roma school children from the 1 st and 272 from the 5 th grade residing in different towns in Macedonia. The control group was recruited from other than Roma ethnic background and consisted of 283 children attending 1st and 356 children attending 5th grade. Every participant was measured for his/hers body height and weight. The t-test and Chi square $\left(X^{2}\right)$ were applied to test statistical significance of variables. The WHO's AnthroPlus software was applied to assess growth parameters and population at risk. There were significant differences in values of the body weight $(\mathrm{p}=0.001)$ and height $(\mathrm{p}=0.001)$ between Roma and non-Roma children attending the 1 st grade of primary school. Weight-for-age, height-for-age and BMl-for-age indexes of the 1st grade children significantly differred in in the same intervals of SD ( $\geq-2 S D$ and $<-1 S D ; \geq-1 S D$ and median; $>+1 S D$ and $\leq+2 S D$; $>+2 S D$ and $\leq+3 S D)$. Except for limited intervals of the SD at BMI-for-age index, there were no significant differences in anthropometric parameters between Roma and non-Roma 5th graders. Anthropometric parameters of nutritional status of Roma children in Macedonia are significantly different than those of their non-Roma peers. Their health risks are predominantly related to underweight. The parameters related to health risks of overweight or obesity are lower in Roma than in non-Roma children.

Key words: nutritional status, Roma, children, health risk, Macedonia

Address for correspondence: I. Spiroski, Institute of Public Health of the Republic of Macedonia, Department of Physiology and Monitoring of Nutrition, 50. Divizija 6, 1000 Skopje, Republic of Macedonia. E-mail: igor.spiroski@gmail.com

\section{INTRODUCTION}

Second half of the 20th century and the beginning of the present one is characterized with an epidemiological transition. There is a significant reduction of the prevalence of the communicable diseases and rapid increase of the prevalence of the chronic noncommunicable diseases (CNCD). In the European region of the World Health Organization (WHO), $75 \%$ of deaths are due to $\mathrm{CNCD}$, the highest proportion compared to other world regions (1). Cardiovascular diseases (CVD) are world's number one cause of death. It is estimated that 18 million people died from CVD in 2008 , representing $40 \%$ of the total deaths in the world (2). Health strategy of the Republic of Macedonia, in its Goal 8 states: "In the Republic of Macedonia, morbidity, mortality, disability and premature death due to leading CVD will be reduced to the lowest possible level" (3). Circulatory diseases are the leading cause of death in the country, accounting for nearly $57 \%$ of all deaths in 2003. The standardized death rate (SDR) per 100,000 inhabitants for circulatory diseases has increased from 527 in 1991 to 599 in 2003, which is more than double that the European Union rate averaging 262.38 in 2003 (4). Increased incidence of CVD is related to significant changes of the social environment in the countries in transition which led to an establishement of market economy and free trade in previously state ruled economies. Interrelation among factors which contributed to these processes and its cumulative effects are very important in relative risk assessment of CNCD. Some of the risk factors are more stressed than others. Risk factors are divided in two groups: those we cannot modify, control and treat and the other which are modifiable. The first ones are: increasing age, male sex (gender) and heredity (including race). The preventable risk factors include: smoking, high blood cholesterol, high blood pressure, physical inactivity, overweight, obesity and diabetes mellitus. Other factors which may also contribute to high CNCD prevalence are individual response to stress and an excessive alcohol drinking (5).

Central role in the epidemiology and prevention of CNCD in children has a "tracking" phenomenon. Some studies stress that following the physical condition and possible lower or higher body weight in early childhood, particularly in vulnerable populations, may predict and prevent future occurrence of the CVD and other CNCD (6). Growth is not a constant in development but process in which nutritional needs are determined according to the specific time schedule influenced by the nutrition and health status (7). Risk factors in children are different from those in adults. 
We have to have in mind children's physiology, influence of the family and the community on their behaviour (8). Starting with breastfeeding $(9,10)$, continuing with adequate feeding patterns of the children, family may play an important role in proper development and nutritional status of the child and his/her prevention from developing obesity as one of the most important risk factors for CNCD. The role of school environment is also very important, if children's nutrition is organized collectively in the school, and specific nutritional recommendations are followed. Raising the awareness of children about the importance of healthy nutrition and adequate nutritional status may also influence their future attitudes towards nutrition and health. Rare researches done in the Republic of Macedonia on this issue show that the highest rate of overweight and obesity is detected among children attending kindergartens (age 5) and it reduces as children grow (11). In 2007, the WHO introduced growth reference data for children from 5 to 19 years of age. Subsequently, they revised existing references which, as it was concluded, underestimated the prevalence of childhood obesity (12). The new curves are closely aligned with the WHO child growth standards at the age 5 , and the recommended adult cut-offs for overweight and obesity at the age of 19. They fill the gap in growth curves and provide an appropriate reference for the 5 to 19 years age group (13). Research focused on the health status of Roma, done in different countries, shows that the disease rates are highest in this population, they have lower life expectancy and high rates of child mortality. According to the study done by the Open Society Institute in the Czech Republic in 2001, life expectancy of the Roma women is 15 years shorter than in the other populations. For the Roma men it is 12 years. The United Nations Children's Fund (UNICEF) study in Serbia showed that child mortality rates in Roma children at age 5 and less were three times higher than the national average value in this country (14). According to the last census in the Republic of Macedonia in 2002, 53,879 people belong to the Roma community which represents $2.66 \%$ of the total population of the country (15). But other studies based on different study techniques indicate that this number is bigger and ranges between 80,000 and 135,000 Roma people in Macedonia (16). Basic characteristics of the situation with Roma people in Southeastern Europe are also valid for Macedonia: high poverty rate, unemployment, marginalized poor settlements, substandard infrastructure, low health status, low educational level and inappropriate representation in political and public sphere (17) The Vulnerability study (18) produced by the United Nations Development Programme (UNDP) states that $22 \%$ of Roma men and $39 \%$ of Roma women don't have or have incomplete education (compared to $8 \%$ of the non-Roma population living in proximity to Roma people). In the same study it was found that $65 \%$ of Roma men and $83 \%$ of Roma women have never been employed (50\% in non-Roma population living in proximity to Roma people). More than that, $27 \%$ of Roma men and $31 \%$ of Roma women suffered from chronic diseases (23\% in non-Roma population living in proximity to Roma people). Macedonia study shows that three times more Roma people live below poverty line compared to non-Roma living in proximity to Roma people. Few important state documents support the activities directed towards Roma community in the Republic of Macedonia. The National Health Action Plan is designed to support the implementation of the Millennium Development Goals (MDG) and the Decade for
Roma Inclusion (DRI) 2005-2015, adjusted to the local health needs of the Roma population. Implementations of the foreseen activities of this plan include: positive discrimination of Roma, special preventive programs, health promotion, improvement of the primary health care and inclusion of Roma in health policy (19). According to the comparative summary of the activities, which are part of the DRI 2005-2015, and refer to 2005 and 2006, Macedonia is evaluated with an average mark of the indicators of 1.37 and occupies 7 th place out of 9 countries evaluated (Hungary being first and Montenegro last). The unfavourable situation results from relying on measures financed by foreign donators, not on governmental leadership in convoying the Decade programs (20). Still, in the updated version of the comparative summary for 2007, Macedonia is described as "the most active reformer" among all countries which have signed the DRI and is ranked 3rd, scoring significant improvement in comparison with the previous evaluation. This is due to inclusion of Roma people in general public policy, increased employment and provision of better health services for this ethnic group (21). Sub-regional study about Roma children in Southeastern Europe concludes that exclusion from the society affects Roma children even before they are born due to attitudes of major population to their community. Countries in the region have not succeeded to assure decent pre and post natal care for Roma mothers and their children (22). Considering health status of Roma, the findings of the current literature mutually consent on three reasons for their health problems:

1. There is little and insufficient data on the health status of the Roma population;

2. Existing data show that there are huge differences between the health status of the Roma and the major population in the areas where Roma are minority;

3. Poor health status of the Roma is closely connected with their low socioeconomic status (23).

There have not been enough studies on the health status of the Roma children carried out and there is even less data on their nutritional status. Lambert et al. suggest that there are number of problems in collection of data about nutritional status of children and adolescents in Europe. That is due to incomparability of the data since different methods have been used by different projects in Europe. They also conclude that the number of researches is too small to be able to draw conclusions about the nutritional status of children in Europe (24). According to Hajioff and McKee, $70 \%$ of the available papers related to health of Roma people are published in 4 countries: Spain, the Czech Republic, Slovakia and Hungary (25).

The studies related to Roma children in Macedonia are very rare and there is no existing data on the nutritional status of this population which may be used as a guideline for an early detection and possible prevention of the CVD and other CNCD. One of the previous surveys done by UNICEF indicates that Roma children aged 6 to 59 months are most represented in the overall group of children with low z-score for height-for-age. The same study shows that Roma children are breastfed at similar rates as the children from other ethnic groups (26). Available data from the study conducted in Shuto Orizari show that around 38\% of children living in the biggest Roma settlement on the Balkans are at the age of 7 to 14 , i.e. school age. Percentage of children living there with no health insurance is $21.21 \%$. Considering their health status, most frequent are respiratory diseases (27). The Institute 
of Public Health of the Republic of Macedonia (IPH) does annual assessment of the nutritional status of the school age population, but the Roma children has never been analyzed as separate vulnerable group regarding characteristics of their nutritional status. Even more, there is no data for comparison of Roma children to their non-Roma peers in the country. The main objective of our research was to identify the nutritional status of school age Roma children attending 1st and 5th grade of primary school in the Republic of Macedonia with the aim of early detection of the precursors of possible health risks.

\section{MATERIAL AND METHODS}

The research was designed as comparative case control study. We have measured 1140 children. The Roma population group consisted of 501 children ( 229 from 1 st and 272 from 5th grade) who attended primary school in different towns in the Republic of Macedonia. Control group consisted of 639 (283 from 1st and 356 from 5 th grade) non-Roma children. Out of schools included 2 were in the capital, Skopje, and 1 school each in town of Prilep, Bitola, Gostivar, Delcevo, Berovo and Kocani. Schools' management teams were informed about motives and goals of the research and they informed parents of the children to obtain voluntary and conscious agreement with participation in the study. The children whose parents' consent was not received were not included in the examination. The research was conducted during the period of March-June 2008. The main instrument of the research was the questionnaire which consisted of 2 parts, the first one providing the basic information data about the child (name, gender, date of birth, place of birth, all obtained from the individual school records) and the second one dealing with the anthropometric data.

Every child was measured for his/her height and weight. The measurements were done with ambulant instrument which has integrated stadiometer and decimal weight scale. Anthropometric indexes were used for interpretation of the measurements. The following indexes recommended by the WHO were used: height-for-age, weight-for-age and BMI-for-age. The assessment of the values of indexes was done in accordance with the recommended z-scores of SD and percentile charts for the appropriate age group (28). Cut-off points accounted for parameters of growth and health risks were $<-2$ SD for weight-for-age and height-for-age indexes, and $<-2$ SD and $>+1$ SD for the BMIfor-age index, as measurement for thinness and overweight/ obesity. Values of the BMI-for-age $<-2$ SD represent thinness and values $<-3 \mathrm{SD}$ represent severe thinness. For the association of the BMI-for-age with overweight and obesity, values >+1SD represent overweight (equivalent to BMI $25 \mathrm{~kg} / \mathrm{m}^{2}$ at 19 years) and $>+2$ SD represent obesity (equivalent to BMI $30 \mathrm{~kg} / \mathrm{m}^{2}$ at 19 years). Presentation and interpretation of the anthropometric indexes was done by software application for nutritional status assessment of children, specially developed by the IPH, in which new WHO child growth standards and references were incorporated. For statistical processing of the obtained data we used Microsoft Excel 2003 and SPSS 16.00 for Windows. The following methods of analytical statistics were applied for hypothesis testing and drawing conclusions: Student's t-test for association between defined characteristics and Pearson's
Chi-square $\left(\chi^{2}\right)$ for association between independent samples. $\mathrm{P}$ values lower than 0.05 were considered significant. Confidence interval (CI) of $95 \%$ was used. We've calculated and identified groups of population at risk for every anthropometric index with WHO AnthroPlus software.

\section{RESULTS}

In the 1st grade children, 121 (52.6\%) Roma boys and 109 (47.4\%) Roma girls were measured. Gender distribution in the 1 st grade children of the control group was $141(49.8 \%)$ boys and $142(50.2 \%)$ girls. In the 5th grade, $127(46.7 \%)$ boys and 145 $(53.3 \%)$ girls from the Roma group, and 169 (47.5\%) boys and $187(52.5 \%)$ girls from the control group were measured.

Age distribution of children by school grade is presented in Table 1. Because of the large age differences between Roma and non-Roma children in 1st grade, and for the purpose of having possibility to compare the significance of the differences between children's height and weight, we filtered the database for those children to comprise only children 7 to 8 years old from both Roma and control group children on the day when the measurements were taken $(\mathrm{N}=256)$. For the children in 5 th grade the same was done, even though the age differences in that population were not as big as in the 1st grade, so it comprised children aged 11 to 12 from both population groups $(\mathrm{N}=598)$.

\section{Weight and Height}

The values of body weight and height of Roma and the children from the control group were tested for significance by t-test. The results showed that both indicators were significantly different in the 1 st grade children. The same indicators did not show statistically significant differences among 5 th graders of both populations (Tables 2 and 3 ).

\section{Anthropometric Indexes \\ Height-for-Age}

We examined significance of the differences of the heightfor-age index among different intervals of SD by using $\chi^{2}$ test. The results in 1st graders showed that the significant differences were present at following intervals of SD $(\mathrm{p}<0.05)$ : $\geq-2 \mathrm{SD}$ and $<-1 \mathrm{SD} ; \geq-1 \mathrm{SD}$ and Median; $>+1 \mathrm{SD}$ and $\leq+2 \mathrm{SD} ;>+2 \mathrm{SD}$ and $\leq+3 \mathrm{SD}$. There were not significant differences in any z-scores of SD among 5 th graders.

Table 1. Age distribution

\begin{tabular}{|l|c|c|c|}
\hline & Number (N) & $\begin{array}{c}\text { Average age } \\
\text { (years) }\end{array}$ & SD \\
\hline 1st grade \\
\hline Roma & 212 & 7.24 & 0.48 \\
\hline Control group & 278 & 6.53 & 0.63 \\
\hline 5th grade \\
\hline Roma & 242 & 11.24 & 0.52 \\
\hline Control group & 356 & 11.09 & 0.46 \\
\hline
\end{tabular}


Table 2. Comparison of weight and significance of the differences among populations

\begin{tabular}{|c|c|c|c|c|}
\hline & Number (N) & $\begin{array}{c}\text { Average } \\
(\mathrm{kg})\end{array}$ & SD & $p$ \\
\hline \multicolumn{5}{|l|}{1 st grade } \\
\hline Roma & 151 & 25.56 & 6.12 & \multirow{2}{*}{0.001} \\
\hline Control group & 105 & 28.49 & 7.02 & \\
\hline \multicolumn{5}{|l|}{5 th grade } \\
\hline Roma & 242 & 42.90 & 11.63 & \multirow{2}{*}{0.43} \\
\hline Control group & 356 & 43.64 & 11.19 & \\
\hline
\end{tabular}

Table 3. Comparison of height and significance of the differences among populations

\begin{tabular}{|c|c|c|c|c|}
\hline & Number (N) & $\begin{array}{c}\text { Average } \\
(\mathrm{cm})\end{array}$ & SD & $p$ \\
\hline \multicolumn{5}{|l|}{ 1st grade } \\
\hline Roma & 151 & 125.36 & 6.01 & \multirow{2}{*}{0.001} \\
\hline Control group & 105 & 128.24 & 6.26 & \\
\hline \multicolumn{5}{|l|}{5 th grade } \\
\hline Roma & 242 & 150.67 & 7.78 & \multirow{2}{*}{0.44} \\
\hline Control group & 356 & 150.18 & 7.45 & \\
\hline
\end{tabular}

\section{Weight-for-Age}

Weight-for-age index is only used for nutritional status assessment of children 10 years old and younger. In this study it was used only for children who attended 1st grade of primary school. We have examined the significance of the differences of the weight-for-age index among different $\mathrm{z}$-scores of SD. The results showed that the significant differences were present at following intervals of $\mathrm{SD}(\mathrm{p}<0.05)$ : $\geq-2 \mathrm{SD}$ and $<-1 \mathrm{SD} ; \geq-1 \mathrm{SD}$ and Median; $>+1$ SD and $\leq+2 \mathrm{SD} ;>+2 \mathrm{SD}$ and $\leq+3 \mathrm{SD}$.

\section{Body Mass Index-for-Age (BMI-for-Age)}

Statistically significant differences $(p<0.05)$ of the $z$-scores of $\mathrm{SD}$ for the BMI-for-age index among the 1st grade children were present at the following intervals: $\geq-2 \mathrm{SD}$ and $<-1 \mathrm{SD} ; \geq-1 \mathrm{SD}$ and Median; $>+1$ SD and $\leq+2 \mathrm{SD} ;>+2 \mathrm{SD}$ and $\leq+3 \mathrm{SD}$. Among the 5 th grade children, significant differences $(\mathrm{p}<0.05)$ were present at: $\geq-2$ SD and $<-1$ SD; $\geq-1$ SD and Median; $>+1$ SD and $\leq+2$ SD.

\section{Evaluation of Anthropometric Parameters}

The percentages of the population at risk classified according to the anthropometric parameters are presented at Tables 4 and 5. Risk assessment classification was done using cut-off points recommended by the WHO. From the data presented, it is noticeable that there is higher percentage of Roma children, compared to non-Roma, who are at risk of underweight, both in the 1 st and in 5 th grade. Comparison of studied populations shows that non-Roma children are at higher risk of overweight and obesity compared to their Roma peers, both in the 1st and in 5th grade.

\section{DISCUSSION}

Roma population in Macedonia, as in most countries where they live in, is vulnerable. They are socially most disadvantaged, with low financial income, most of them unemployed with no health insurance, even not fully represented in the official country statistics because of not-reported newborns, death persons, etc. Roma children are in addition affected because of the living patterns of their families. This is even more pronounced in developed,

Table 4. Children at risk using WHO cut-off points for anthropometric indexes, 1 st grade

\begin{tabular}{|c|c|c|c|c|c|c|c|}
\hline & $\begin{array}{c}\%<-3 S D \\
(95 \% \mathrm{Cl})\end{array}$ & $\begin{array}{c}\%<-2 \mathrm{SD}^{1} \\
(95 \% \mathrm{Cl})\end{array}$ & $\begin{array}{c}\%>+1 \mathrm{SD}^{2} \\
(95 \% \mathrm{Cl})\end{array}$ & $\begin{array}{c}\%>+2 \mathrm{SD}^{3} \\
(95 \% \mathrm{Cl})\end{array}$ & $\begin{array}{c}\%>+3 S D \\
(95 \% \mathrm{Cl})\end{array}$ & Mean & SD \\
\hline \multicolumn{8}{|c|}{ Weight-for-age } \\
\hline Roma & $\begin{array}{c}0.5 \\
(0 \%, 1.6 \%)\end{array}$ & $\begin{array}{c}1.9 \\
(0 \%, 4 \%)\end{array}$ & & & & 0.03 & 1.20 \\
\hline Non-Roma & $\begin{array}{c}0 \\
(0 \%, 0.2 \%)\end{array}$ & $\begin{array}{c}0.7 \\
(0 \%, 1.9 \%)\end{array}$ & & & & 0.88 & 1.31 \\
\hline \multicolumn{8}{|c|}{ Height-for-age } \\
\hline Roma & $\begin{array}{c}0 \\
(0 \%, 0.2 \%)\end{array}$ & $\begin{array}{c}1.9 \\
(0 \%, 4 \%)\end{array}$ & & & & 0.03 & 1.07 \\
\hline Non-Roma & $\begin{array}{c}0 \\
(0 \%, 0.2 \%)\end{array}$ & $\begin{array}{c}0 \\
(0 \%, 0.2 \%)\end{array}$ & & & & 0.73 & 1.1 \\
\hline \multicolumn{8}{|l|}{ BMI-for-age } \\
\hline Roma & $\begin{array}{c}0.5 \\
(0 \%, 1.6 \%) \\
\end{array}$ & $\begin{array}{c}4.8 \\
(1.6 \%, 7.9 \%)\end{array}$ & $\begin{array}{c}18.6 \\
(13.1 \%, 24.1 \%) \\
\end{array}$ & $\begin{array}{c}8.1 \\
(4.2 \%, 12 \%)\end{array}$ & $\begin{array}{c}5.2 \\
(2 \%, 8.5 \%) \\
\end{array}$ & -0.01 & 1.33 \\
\hline Non-Roma & $\begin{array}{c}0 \\
(0 \%, 0.2 \%)\end{array}$ & $\begin{array}{c}1.8 \\
(0.1 \%, 3.6 \%)\end{array}$ & $\begin{array}{c}35.4 \\
(29.6 \%, 41.2 \%)\end{array}$ & $\begin{array}{c}19.5 \\
(14.6 \%, 24.3 \%)\end{array}$ & $\begin{array}{c}5.8 \\
(2.8 \%, 8.7 \%)\end{array}$ & 0.65 & 1.38 \\
\hline
\end{tabular}

$1 \%<-2$ SD includes $\%<-3 S D$

$2 \%>+1$ SD includes $\%>+2$ SD and $\%>+3 S D$

$3 \%>+2 S D$ includes $\%>+3 S D$ 
Table 5: Children at risk using WHO cut-off points for anthropometric indexes, 5th grade ${ }^{4}$

\begin{tabular}{|c|c|c|c|c|c|c|c|}
\hline & $\begin{array}{c}\%<-3 S D \\
(95 \% \mathrm{CI})\end{array}$ & $\begin{array}{c}\%<-2 S D^{5} \\
(95 \% \mathrm{Cl})\end{array}$ & $\begin{array}{c}\%>+1 \mathrm{SD}^{6} \\
(95 \% \mathrm{Cl})\end{array}$ & $\begin{array}{c}\%>+2 \mathrm{SD}^{7} \\
(95 \% \mathrm{Cl})\end{array}$ & $\begin{array}{c}\%>+3 S D \\
(95 \% \mathrm{Cl})\end{array}$ & Mean & SD \\
\hline \multicolumn{8}{|c|}{ Height-for-age } \\
\hline Roma & $\begin{array}{c}0 \\
(0 \%, 0.2 \%)\end{array}$ & $\begin{array}{c}2.1 \\
(0.1 \%, 4.1 \%)\end{array}$ & & & & 0.34 & 1.16 \\
\hline Non-Roma & $\begin{array}{c}0 \\
(0 \%, 0.1 \%)\end{array}$ & $\begin{array}{c}0.3 \\
(0 \%, 1 \%)\end{array}$ & & & & 0.41 & 1.08 \\
\hline \multicolumn{8}{|c|}{ BMI-for-age } \\
\hline Roma & $\begin{array}{c}0.4 \\
(0 \%, 1.4 \%)\end{array}$ & $\begin{array}{c}3.7 \\
(1.1 \%, 6.3 \%)\end{array}$ & $\begin{array}{c}26.9 \\
(21.1 \%, 32.7 \%)\end{array}$ & $\begin{array}{c}9.1 \\
(5.3 \%, 12.9 \%)\end{array}$ & $\begin{array}{c}2.5 \\
(0.3 \%, 4.6 \%)\end{array}$ & 0.14 & 1.37 \\
\hline Non-Roma & $\begin{array}{c}0.6 \\
(0 \%, 1.5 \%)\end{array}$ & $\begin{array}{c}4.5 \\
(2.2,6.8 \%)\end{array}$ & $\begin{array}{c}35.7 \\
(30.6 \%, 40.8 \%)\end{array}$ & $\begin{array}{c}12.4 \\
(8.8 \%, 15.9 \%)\end{array}$ & $\begin{array}{c}2 \\
(0.4 \%, 3.5 \%)\end{array}$ & 0.4 & 1.35 \\
\hline
\end{tabular}

${ }^{4}$ Weight-for-age reference data are not available beyond age 10 because this indicator does not distinguish between height and body mass in an age period where many children are experiencing the pubertal growth spurt and may appear as having excess weight (by weight-for-age) when in fact they are just tall

$5 \%<-2$ SD includes $\%<-3 S D$

$60>+1$ SD includes $\%>+2$ SD and $\%>+3 S D$

$7 \%>+2 S D$ includes $\%>+3 S D$

compared to developing countries, as there is a clear association between nutrition and inequities in health. Study by James et al. proves that there are big differences in health between rich and poor strata of the society (29). People representing low social status groups have higher prevalence of obesity, high blood pressure, high levels of serum cholesterol and anemia and they are more likely to experience premature death from coronary heart disease or cancer. Children from those groups have lower birth weight, abnormalities at birth, impaired growth or die in perinatal period. Those children, living in areas of high deprivation from different social services have higher levels of obesity. Study by Jotangia et al. showed that obesity levels in that kind of environments is $16.4 \%$ compared to $11.2 \%$ in areas of lowest deprivation defined by Index of Multiple Deprivation (30). The study about relation of the social characteristics and nutritional status was conducted in Argentina. Hirchler et al. did it in 4 primary schools in Buenos Aires and found that $18.5 \%$ of children were obese and $16.1 \%$ were overweight (31). One research done by the World Bank showed that enrolment of Roma children in primary schools is 20 to $33 \%$ lower compared to other children and their early drop out from school is more than twice higher compared to their peers influences their lower education level and poverty (32). Our results show that the difference in age between Roma and non-Roma children is large in 1st grade. Reasons for that vary, from the late school enrolment of Roma children to the reform of the school system in general, which was implemented in the school year when the study was conducted. Roma children, mostly under influence of their families, start their education later than other children. By talking to teachers in schools we were informed that those children are frequently absent from school. However, once enrolled in the education process this fact is often misused by their families for gaining benefits offered by the state. Results from our study also show that there is significant difference in all anthropometric characteristics of Roma children and those from control group who attend 1st grade of primary school. Those differences are significantly reduced in 5th grade children which is an indication that during their growth, Roma children reach the anthropometric characteristics of their 5th grade non-Roma peers. In our research we conclude that health risks of Roma children are predominantly related to underweight. On the other hand, children from other ethnic background have higher health risks related to overweight and obesity. Further research, which will follow the same cohort and include more variables, will be crucial to track future development, health status and reasons for possible health impairments in these children. One of the rare studies focusing on both perspectives of the impairment of the nutritional status (underweight and overweight/obesity) is conducted by Wang et al. from the Institute of Nutrition and Hygiene and Chinese Academy for Preventive Medicine in cooperation with University of South Carolina (33). In this study children cohort was followed over the period of 6 years. It was concluded that there was very little research done on describing the dynamics of the phenomenon of the undernutrition in children. Children have usually slower growth during the pre-school period and catch up later during the school years. Early detection of health risks among vulnerable ethnic groups is often stressed as crucial (34). Still, those risks may often remain unrecognized according to Lacey Benson and her colleagues (35). Analysis of data from electronic medical records encompassed 60,711 patients aged 2 to 18 years who had at least 1 well-child visit at a large academic medical system in northeast Ohio between June 1999 and October 2007. Retrospective review of body mass index (BMI) measurements during the study period showed that $19 \%$ of the children were overweight, $23 \%$ were obese, and $8 \%(33 \%$ of the obese patients) were severely obese. However, these conditions were diagnosed in only $10 \%$ of the overweight patients, $54 \%$ of the obese patients, and $76 \%$ of the severely obese patients. Factors that were positively associated with diagnosis were BMI, age, number of overweight visits, female sex, and black or Hispanic vs. white race.

Our study had a goal to approach one, until now, not investigated area of determination of the nutritional status of the population group of school-age Roma children and to compare their anthropometric characteristics with those of their non-Roma peers in the Republic of Macedonia. By identifying anthropometric characteristics and growth parameters of the examined popula- 
tion we succeeded to categorize their health risks, both from undernutrition and overweight/obesity.

\section{Acknowledgements}

The authors would like to gratefully acknowledge the assistance provided by Ms. Monika Barbara Bloessner from the World Health Organization, who contributed in some of the statistical analyses and provided valuable inputs on data interpretation.

\section{Statement on conflict of interests and sponsorship}

The authors declare that they have no conflicts of interests.

This study was financially supported by Open Society Institute Macedonia (OSIM Research Grant No. 8387).

\section{REFERENCES}

1. World Health Organization. The challenges of obesity in the WHO European Region. Copenhagen: WHO Regional Office for Europe; 2005.

2. World Health Organization. World Health Report 2008: primary health care (no more than ever). Geneva: WHO; 2008.

3. Ministry of Health of the Republic of Macedonia. Health strategy of the Republic of Macedonia 2020: secure, efficient and just health care system. Skopje: Ministry of Health of the Republic of Macedonia; 2007.

4. Gjorgjev D, Bacanovic A, Cicevalieva S, Sulevski Z, Grosse-Tebbe S. The Former Yugoslav Republic of Macedonia: health system review. Health Systems in Transition. 2006;8(2):1-98.

5. American Heart Association. Risk factors and coronary heart disease [Internet]. Dallas: American Heart Association; 2011 [updated 2011; cited 2011 March 4]. Available from: http://www.americanheart.org/presenter. jhtml?identifier $=4726$.

6. Kristensen PL, Wedderkopp N, Møller NC, Andersen LB, Bai CN Froberg K. Tracking and prevalence of cardiovascular disease risk factors across socio-economic classes: a longitudinal substudy of the European Youth Heart Study. BMC Public Health. 2006 Jan 27;6:20.

7. Tulchinsky TH, Varavikova EA. The new public health. 2nd ed. Amsterdam: Elsevier Academic Press; 2009.

8. Hawkins SS, Law C. A review of risk factors for overweight in preschool children: a policy perspective. Int J Pediatr Obes. 2006;1(4):195-209.

9. Novotny R, Coleman P, Tenorio L, Davison N, Camacho T, Ramirez V, et al. Breastfeeding is associated with lower body mass index among children of the Commonwealth of the Northern Mariana Islands. J Am Diet Assoc. 2007 Oct;107(10):1743-6.

10. Division of Nutrition and Physical Activity. Does breastfeeding reduce the risk of pediatric overweight? Research to Practice Series No. 4. Atlanta: Centers for Disease Control and Prevention; 2007.

11. Dimitrovska Z, Spiroski I, Gudeva-Nikovska D, Kendrovski V, Aleksoski B. Prevalence of overweight and obesity in children and adolescents in Macedonia. Proceedings of th 2nd Balkan Congress on Obesity; 2006 May 19-21; Albena, Bulgaria; 2006.

12. de Onis M. Growth curves for school age children and adolescents. Indian Pediatr. 2009 Jun;46(6):463-5.

13. de Onis M, Onyango AW, Borghi E, Siyam A, Nishida C, Siekmann J. Development of a WHO growth reference for school-aged children and adolescents. Bull World Health Organ. 2007 Sep;85(9):660-7.

14. Republic Institute for Health Protection. Situation of nutrition at Roma population and recommendations for overcoming of the detected problems. Skopje: Republic Institute for Health Protection; 2007.
15. State Statistical Office of the Republic of Macedonia. Census of population, households and dwellings in the Republic of Macedonia, 2002. Skopje: State Statistical Office of the Republic of Macedonia; 2005.

16. Durmis D, Memedov A, Demir Lj. Assessment of the needs of Roma educational fund, Macedonia. Skopje: The World Bank Country Office; 2004

17. Pavlovski B. Health, health protection and influences on health of Roma in Macedonia. Skopje: Association for emancipation, solidarity and equality of women in the Republic of Macedonia; 2008. (In Macedonian.)

18. United Nations Development Programme. Faces of poverty, faces of hope: vulnerability profiles for Decade of Roma Inclusion countries. Bratislava: UNDP; 2004.

19. Tozija F. Social inclusion of Roma population in health: situation, challenges and opportunities. J Soc Policy. 2008;1:58-67.

20. Decade Watch. Roma activists assess the progress of the Decade of Roma Inclusion, 2005-2006. Budapest: Createch Ltd; 2007.

21. Decade Watch. Roma activists assess the progress of the Decade of Roma Inclusion. 2007 Update. Budapest: Createch Ltd; 2008.

22. United Nations Children's Fund. Breaking the cycle of exclusion: Roma children in Southeast Europe. Belgrade: UNICEF; 2007.

23. Open Society Institute. Facing the hidden disease: tuberculosis in Roma communities. New York: Open Society Institute; 2007.

24. Lambert J, Agostoni C, Elmadfa I, Hulshof K, Krause E, Livingstone B, et al. Dietary intake and nutritional status of children and adolescents in Europe. Br J Nutr. 2004 Oct;92 Suppl 2:S147-211.

25. Hajioff S, McKee M. The health of the Roma people: a review of the published literature. J Epidemiol Community Health. 2000 Nov;54(11):864-9.

26. United Nations Children's Fund. Multiple Indicator Cluster Survey Macedonia. Skopje: UNICEF; 2001

27. Lakinska-Popovska D. Vulnerability of Roma children in the municipality of Shuto Orizari. Skopje: UNICEF; 2000.

28. Pollozhani A, Dimitrovska Z, Kendrovski V, Spiroski I. Nutritional anthropometry: measurements, indicators, indexes, nutritional status. Skopje: Institute of Public Health of the Republic of Macedonia; 2009. (In Macedonian.)

29. James WP, Nelson M, Ralph A, Leather S. Socioeconomic determinants of health. The contribution of nutrition to inequalities in health. BMJ. 1997 May 24;314(7093):1545-9.

30. Jotangia D, Moody A, Stamatakis E. Wardle H. Obesity among children under 11. London: Department of Health; 2005.

31. Hirschler V, Buzzano K, Erviti A, Ismael N, Silva S, Dalamon R. Overweight and lifestyle behaviors of low socioeconomic elementary school children in Buenos Aires. BMC Pediatr. 2009 Feb 24;9:17.

32. Revinga A, Ringold D, Tracy WM. Poverty and ethnicity: a cross country study of Roma poverty in Central Europe. Washington: The World Bank; 2002 .

33. Wang Y, Ge K, Popkin BM. Tracking of body mass index from childhood to adolescence: a 6-y follow-up study in China. Am J Clin Nutr. 2000 Oct;72(4):1018-24.

34. Freedman DS, Khan LK, Serdula MK, Dietz WH, Srinivasan SR, Berenson GS. Racial differences in the tracking of childhood BMI to adulthood. Obes Res. 2005 May;13(5):928-35.

35. Benson L, Baer HJ, Kaelber DC. Trends in the diagnosis of overweight and obesity in children and adolescents: 1999-2007. Pediatrics. 2009 Jan;123(1):e153-8. 